\title{
Embracing Marketing Operations: What's in it for DAM professionals?
}

\section{Gary M. Katz}

is CEO and founder of Marketing Operations Partners, a Santa Clara, California-based services and solutions firm focused on changing the $\mathrm{MO}$ of marketing by helping $\mathrm{CMOs}$ leverage process, technology, guidance and metrics to run marketing like a fully accountable business. For more information, visit www.mopartners.com.

Keywords: marketing operations, ROI, change management, IT, metrics, technology initiatives

Abstract The emergence of Marketing Operations as a formalized discipline in enterprise today creates tremendous opportunity for DAM professionals and buyers alike. Marketing Operations paves the path for DAM, MOM and other comprehensive technology initiatives by:

- spawning a new breed of professionals whose sole purpose is to improve efficiency and effectiveness of their enterprises' marketing departments;

- injecting left-brain thinking into the typically right-brained-heavy Marketing function;

- building a marriage between Marketing and IT, as well as other interdependent stakeholders;

- creating a predisposition toward deploying Marketing automation solutions to address such challenges as optimizing scarce resources, capturing $\mathrm{ROI}$ insight and sharing knowledge.

In fact, it is fair to say that the abbreviation for Marketing Operations (MO) is an apt descriptor of its potential impact in organizations. Marketing Operations is poised to literally change the modus operandi of Marketing. And a new MO for Marketing in organizations is great news for all of us. So whether you're a DAM project manager or business user, it is definitely in your best interest to become a passionate advocate of Marketing Operations.

Journal of Digital Asset Management (2007) 3, 43-49. doi:10.1057/palgrave.dam.3650056

\section{INTRODUCTION}

At the recent Digital Asset Management/

Marketing Operations Management Symposium in Hollywood, I observed that our community is still much more focused on building a DAM than spreading MOM's love. I watched hundreds of people roam in and out of the DAM sessions, while the one room with us MOMma's boys (and girls) might have reached 80 at the peak.

Of course, DAM has about a five-year headstart in building traction compared to MOM, and companies such as IBM have seen incredible ROI from DAM efforts, so it is not that surprising where the action is.

So for the time being, at least, I'm resigned to the fact that DAM will get the most attention, and MOM will be the classic secondborn child trying desperately to beat out the older sibling for the reigns of the family business.

There is, however, a third child in the mix that we all tend to forget, and the success of this child may well dramatically transform the fate of DAM, MOM and the rest of the Acronym family. The name of this "invisible" child: Marketing Operations (MO).

The emergence of $\mathrm{MO}$ as a formalized discipline in enterprise today creates tremendous opportunity for all of us. MO paves the path for DAM, MOM and other comprehensive technology initiatives by:

- spawning a new breed of professionals whose sole purpose is to improve efficiency and effectiveness of their enterprises' marketing departments;

- injecting left-brain thinking into the typically right-brained-heavy Marketing function; 
- building a marriage between Marketing and IT, as well as other interdependent stakeholders;

- creating a predisposition toward deploying Marketing automation solutions to address such challenges as optimizing scarce resources, capturing ROI insight and sharing knowledge.

In fact, it is fair to say that the abbreviation for Marketing Operations - MO - is an apt descriptor of its potential impact in organizations. Marketing Operations is poised to literally change the modus operandi of Marketing.

And a new modus operandi for Marketing in organizations is great news for all of us. So whether you are a DAM project manager or business user, it is definitely in your best interest to become a passionate advocate of $\mathrm{MO}$.

\section{WHAT IS MO?}

Admired companies (like Intel, Bank of America and Google) are leveraging MO to improve performance and measure ROI as they refine their marketing organizations using an operational focus. $\mathrm{MO}$ is an emerging discipline that increases efficiency and drives consistent results in complex marketing organizations. It builds a foundation for excellence by reinforcing marketing strategy with processes, technology, best practices and metrics. Organizations that embrace $\mathrm{MO}$ are enabling Chief Marketing Officers (CMOs) to run Marketing as a profit center and fully accountable business. In essence, MO provides the CMO with an operational partner, similar to the Chief Operating Officer (COO)/Chief Executive Officer (CEO) relationship.

In a nutshell, MO:

- brings a long overdue operational focus to Marketing;

- employs the application of proven and time-tested business processes and best practices in the Marketing organization;

- establishes a discipline to increase efficiency and drive consistent results;

- creates a solid foundation for Marketing excellence.

\section{THE BODY OF KNOWLEDGE BEHIND MO}

$\mathrm{MO}$ is a very complex topic, integrating what is already a broad and rapidly expanding body of knowledge with insight from a variety of other fields. The list of contributors includes, but is not limited to:

- change management;

- quality;

- manufacturing;

- organizational reengineering;

- IT;

- supply chain management;

- statistical analysis;

- financial management;

- customer relationship management;

- enterprise resource management;

- training;

- knowledge management;

- corporate governance;

- sales pipeline management.

\section{HOW MO SOLVES “THE SEVEN DEADLY MARKETING SINS"}

Busy marketing groups can be so focused on tactics and fire fighting that they jeopardize their marketing investment. The tendency to overreact to events, tackle symptoms rather than underlying fundamental problems and jump at the opportunity to please the boss can prove fatal. Crippled marketing efforts can leave promising companies in the dust, or at least handicapped at the starting gate.

While MO is uniquely suited to tackle marketing's most challenging problems in Fortune 500 companies, you do not have to be a GE, Cisco or Bank of America to benefit. Here are the seven deadliest marketing sins that plague companies of all sizes and how $\mathrm{MO}$ addresses them:

\section{Sin \#1: III-defined metrics}

Today's corporate marketing departments must justify their existence. The need to measure results is inevitable. The instincts and skills that make a corporate marketing professional great - a bias toward action, verbal and written acuity and a talent for relationship-building however, often don't translate into an ability or willingness to scientifically and objectively evaluate success.

Broken systems and the unwillingness of the organization to pay for marketing measurement also conspire against the effort to define meaningful success metrics. 
Solution: MO ensures that the right processes are in place to establish meaningful metrics at the front-end of marketing process, enabling success measurement processes at key intervals and as each program concludes.

\section{Sin \#2: Slammed resources}

The prevailing attitude of "doing more with less" can leave key people discouraged and overwhelmed, near burnout - and, eventually, circulating their resumes. The consequences for organizations are costly mistakes, high turnover, collapsed programs when key people leave and missed opportunities to leverage important, but ownerless, programs.

Solution: MO addresses resource limitations by ensuring workload is effectively allocated, roles are clearly defined, interdependencies are understood, team members feel satisfied with their jobs and valued-added programs and associated resources - whether through additional headcount or outsourcing - can be justified to executive management.

\section{Sin \#3: Sketchy institutional memory}

Successful marketing programs depend on accurate information, a historical view into past successes and failures and the ability to recognize patterns that link seemingly unrelated data points. DAM adopters and professionals have an intimate understanding of this issue.

Unfortunately, in many marketing organizations with poor knowledge management systems and processes, this crucial knowledge is scattered all over the company. It is in the heads of individual workers, on shelves, on people's hard drives and in long forgotten filing systems. Often, when people leave, a big piece of organizational knowledge goes with them. Information loss is a huge productivity killer for marketing teams. Trying to regain this lost insight wastes previous marketing investments.

Solution: MO - through technologies such as DAM, Brand Asset Management (BAM), Marketing portals and a variety of other solutions - facilitates knowledge sharing, creates an enduring repository of information and encourages decision-making based on fact, rather than hunches or gut feelings.

\section{Sin \#4: Constipated creativity}

The best creative solutions come from the collaboration of many brains. A consequence of the age of the "individual-contributor/director" is constrained creativity. When the entire creative burden falls mostly on one corporate marketer, the ability to think out of the box can be severely impacted. Creative synergy results from many minds thinking as one.

Solution: MO enables the creative process to benefit from the synergy of team.

\section{Sin \#5: Dysfunctional team and supplier relationships}

Team collaboration is a real challenge in dynamic — and even stagnant, mature - organizations typically modeled on competition, power and control structures. Over-reliance on legacy systems and tools also perpetuates this problem. At the recent DAM/MOM conference, one company shared how it was using Excel spreadsheets to capture knowledge that required more than 100 columns in width. Such inappropriate use of existing tools is a major obstacle to effective team decision-making processes.

Problematic supplier relationships are also an indicator of trouble. Most successful companies can point to numerous strong, long-term marketing supplier relationships they consider to be integral to their success. Likewise, a pattern of failed supplier relationships is often an indicator of marketing department failure, rather than poor vendor performance. Unfortunately, companies that have had consistently bad relationships with outside vendors and suppliers often react by bringing everything in house. While this strategy may provide the illusion of control, it allows marketing managers to deflect the blame for failures, rather than teaching them how to manage their outsourcing program by taking responsibility for the results. In addition, this "band-aid" strategy would not scale with the organization as it grows.

Solution: MO helps set realistic expectations and mutual accountability between suppliers and the organization, increasing the effectiveness of outsource partners by empowering them to act as an extension of the internal team. 


\section{Sin \#6: Poor fiscal and tactical decision-making}

Budgets are never set in stone. Often, it is a "use it or lose it" situation. For some managers, it is "misuse it and lose it anyway." Unfortunately, many corporate marketing departments end up leaving program budget on the table or allocating it to the wrong initiatives. This "Catch 22marketing budget dilemma" occurs because ...

- It's very time consuming to manage the budget effectively, especially in companies with broken financial systems.

- Each marketing spend-decision creates more work for the one-person or small-team marketing department in terms of project management, measurement, supplier management, etc.

- Doubt persists about the ability to successfully justify the expenditure to management.

- Focus is instinctively on high-visibility marketing activities and C-level executive requests over good fiscal management.

- Most marketing types are inclined toward creativity rather than finance.

Poor budgeting processes and kludged financial/ marketing systems also contribute to perpetuating this sin.

Solution: MO facilitates implementing the system-support infrastructure and financialmanagement discipline needed to protect valuable marketing budgets.

\section{Sin \#7: Inadequate Marketing portfolio}

Many companies align their fate with the success of too few marketing programs whether it is lead generation, public relations, trade shows or advertising. Over-reliance on any one particular program can derail a company, especially if a key program unexpectedly loses momentum. In the meantime, programs that could have had strong leverage never get a chance to prove their mettle and are forever relegated to the "B" list. Classic examples include customer references, lead nurturing and analyst research/consulting subscription ROI management.

In addition, poor intelligence about program ROI also creates a challenge in sustaining the right marketing mix.
Solution: MO puts the means in place to launch potentially high-value marketing programs that would otherwise never get out of the starting gate.

\section{COMPONENTS OF MO}

As discussed previously, $\mathrm{MO}$ is a complex discipline which, depending on the organization, could leverage dozens of different strategies and tactics. To simplify and organize presentation of its components, let us consider how MO addresses each of the following challenges:

- Demonstrating accountability/ROI;

- Value Creation and Innovation;

- Customer Experience Management;

- Alignment with Stakeholders;

- Delivering the Enterprise Strategic Agenda;

- Scaling for Growth;

- Accelerating Demands with Frozen, Tentative Budgets.

Below I have provided a laundry list of $\mathrm{MO}$ solutions that can be employed to address each of the above challenges. This list should not be considered complete.

\section{Demonstrating Accountability/ROI}

- Marketing Analytics;

- Metrics and Key Performance Indicator Definition;

- Dashboard Development;

- Performance Measurement;

- Marketing Portfolio Management;

- Industry Benchmarking;

- Budget Management and Justification.

\section{Customer Experience Management}

- Voice of the Customer/Employee;

- Customer Lifetime Value Assessment and Strategies;

- Customer Loyalty Assessment and Strategies;

- Customer Reference Development.

\section{Value Creation and Innovation}

- Lead Conversion;

- Marketing Automation;

- Knowledge Management; 
- Process Mapping and Design;

- Tool and Template Development;

- Best Practices Documentation;

- Centers of Excellence;

- Marketing Planning;

- Industry Benchmarking Analysis;

- All-Hands Meeting Preparation.

\section{Delivering the Enterprise Strategic Agenda}

- Business Intelligence;

- Marketing Charter Definition;

- Change Management;

- Socialization and Community Building;

- Leadership Council;

- Brand Governance;

- $\mathrm{CMO}$ and Marketing Communications;

- Intranet.

\section{Alignment with Stakeholders}

- Sales and Marketing Alignment;

- Cross-Functional Alignment (for example, Sales, Marketing and Product Development);

- Mergers and Acquisitions Assimilation.

\section{Scaling for Growth}

- Marketing Organization Assessment;

- Marketing Skill and Competency Development;

- Role Clarification;

- Team Mix Modeling;

- Marketing Organizational Reengineering.

\section{Accelerating Demands with Frozen, Tentative Budgets}

- Marketing Resource Optimization;

- Marketing Purchasing;

- Supply Chain Management.

\section{IS IT TIME FOR YOUR ORGANIZATION TO CHANGE ITS MO?}

Now let us identify those characteristics that signal your organization's readiness for $\mathrm{MO}$ and answer these questions: What does that organization look like? What are its primary pain points? What is its vision for the future? What pressures are driving it to consider undergoing substantial change?

\section{MO READINESS: A CHECKLIST FOR YOUR ORGANIZATION}

To see if your company is a good candidate for $\mathrm{MO}$, check all the characteristics listed below that apply.

- My organization is mid-size or larger.

- My organization's marketplace is dynamic and highly competitive.

- My organization's marketing has evolved into a complex and multi-dimensional function.

- My organization has a significant marketing budget.

- A diverse mix of programs and resources are funded to reach a breadth of audiences (segments, sales channels, internal and external stakeholders, etc).

- My organization faces government and regulatory compliance pressures.

- My organization's marketing processes have evolved to the point that they are no longer well coordinated or even well understood.

- My organization values best practices but lacks process, technology and metrics to achieve them.

- My organization is pressuring marketing to assume a more strategic role.

- Within my organization, many believe that marketing must deliver greater value for the company's investment.

If you checked half or more of the above statements, your company is a great candidate to benefit by leveraging the power of $\mathrm{MO}$.

\section{MO READINESS: WHERE DO YOU FEEL THE PAIN?}

If your company is feeling some pain, you are probably acutely aware of it. Arriving at an accurate diagnosis, however, requires a careful examination. Before reviewing the checklist below to identify localized pain points, first consider the general health of your marketing effort. Does marketing currently receive wide recognition for its strategic leadership and bottom-line contribution? Is marketing in complete alignment with your company's strategic goals and other key functions? Can marketing clearly measure its success and demonstrate ROI to your executive team?

MO is specifically designed to address the following enterprise pain points; check how many apply to your organization:

- Marketing is focused on firefighting and tactics rather than on strategy. 
- Marketing experiences difficulty measuring ROI and demonstrating value, causing it often to be on the defensive, needing to justify its role and contribution to C-level executives and investors.

- Marketing success is tied to other groups that have different or even conflicting goals.

- The organizational environment fails to support collaboration and consequently loses opportunities for synergy.

- Employee defections jeopardize continuity, place at risk institutional knowledge and expertise, and contribute to high customer churn.

- Marketing processes too often constrain internal efficiencies and effectiveness instead of enabling them.

- Poor coordination of shared processes exists across functions.

- It is difficult to assimilate and integrate programs, systems and resources obtained from corporate mergers or acquisitions, leading to duplication, momentum loss, lack of focus and resistance to change.

If you resonate with two or more of the above statements, your organization may be in enough pain to be ready to embrace MO.

\section{MO READINESS: WHAT IS YOUR VISION OF MARKETING'S CONTRIBUTION?}

In a perfect world, marketing operates as a very creative, fast-paced, results-driven function that stays close to the customer and its other stakeholders. It is not only aligned with the enterprise's strategic agenda but also helps define it. It leads the customer experience and innovation processes. It is well integrated with other corporate functions and takes full advantage of the power and discipline of a strategically designed $\mathrm{MO}$ infrastructure.

The MO infrastructure layers into the marketing function the processes, technology, guidance and metrics required by an efficient operation that delivers outstanding value on a consistent basis. Such an MO infrastructure enables informed decision making, accountability, sustainability, visibility, teamwork, strategic thinking and repeatable best practices execution.

A marketing organization is ready to think seriously about embracing MO when it feels internal and external pressures to make systemic changes because it has not been delivering on its vision and has consistently failed to achieve its operational goals.

- The CEO considers the CMO/Marketing VP to be a valued strategic partner.

- Marketing is fully aligned with other company functions and stakeholders.

- Marketing efforts accelerate new product adoption, strengthen customer relationships and increase market penetration rate.

- Marketing leverages metrics and dashboards to measure and track results, and continually improve them.

- Dashboards rapidly and accurately inform decision makers.

- Metrics are aligned with corporate goals and increasingly drive marketing expenditures.

- The marketing team is energized and highly effective.

- Employee and customer loyalty are consistently high.

- High return on marketing investment is clearly recognized companywide.

Unless you have checked at least half of the above statements, there is a large gap between your vision and your current reality. Your organization is ripe - or more than ripe - for MO.

Table 1 provides a summary of the characteristics, manifestation of pain and desired vision of organizations that are primed to leverage MO.

\section{MO READINESS: MAKING THE ASSESSMENT}

If you have completed the above checklists, you probably have a good idea whether learning more about MO would be worthwhile. But it is also true that it can be tough for marketing insiders to have a clear and objective view of their own operation. That is where professional can help to assess your organization's readiness to move forward with a new MO.

\section{MO: THE BOTTOM LINE FOR DAM PROFESSIONALS}

Embracing MO is a win-win for everyone, but bringing its benefits into your marketing function should be considered an evolutionary process. $\mathrm{MO}$ is both a serious commitment and a great opportunity. Like all change initiatives, it requires careful and comprehensive thought and exacting 
Table 1: Assessing MO readiness

\begin{tabular}{|c|c|c|}
\hline Characteristic & Organizational pain & Desired vision \\
\hline $\begin{array}{l}\text { Substantial marketing } \\
\text { investment (resources, } \\
\text { programs, budget) }\end{array}$ & $\begin{array}{l}\text { Unmanageable complexity, } \\
\text { difficulty demonstrating ROI, } \\
\text { Marketing on defensive }\end{array}$ & $\begin{array}{l}\text { Marketing optimizes resources to deliver } \\
\text { substantial ROI } \\
\text { - Leverages processes, technology and } \\
\text { best practices to spur productivity, } \\
\text { knowledge sharing } \\
\text { - Utilizes dashboards and metrics to } \\
\text { make informed spend decisions } \\
\text { - Is recognized by C-team for its account } \\
\text { ability and ROI contribution }\end{array}$ \\
\hline $\begin{array}{l}\text { Dynamic, competitive } \\
\text { market }\end{array}$ & $\begin{array}{l}\text { No or disappointing growth, } \\
\text { super-growth, high customer } \\
\text { churn, high employee turnover }\end{array}$ & $\begin{array}{l}\text { Marketing aligns with other functions to } \\
\text { take responsibility for: } \\
\text { - Nurturing sales funnel } \\
\text { - Revenue targets } \\
\text { - Innovation process } \\
\text { - New market penetration } \\
\text { - Customer experience }\end{array}$ \\
\hline $\begin{array}{l}\text { Under media or regulatory } \\
\text { scrutiny for: } \\
\text { - Shareholder confidence } \\
\text { - Supplier to government } \\
\text { - High-profile industry }\end{array}$ & $\begin{array}{l}\text { Compliance pressure, impact } \\
\text { of change on SOX compliance, } \\
\text { media magnifying glass }\end{array}$ & $\begin{array}{l}\text { Marketing partners with Quality, Finance, } \\
\text { IR to meet compliance requirements } \\
\text { - Maps key processes } \\
\text { - Documents best practices } \\
\text { - Applies LEAN, Six Sigma and other } \\
\text { methodologies } \\
\text { - Demonstrates ROI through KPIs, dash } \\
\text { boards, etc }\end{array}$ \\
\hline $\begin{array}{l}\text { M\&A integration challenges } \\
\text { - Actual or pending }\end{array}$ & $\begin{array}{l}\text { Duplicated efforts, loss of } \\
\text { continuity, "everything needs } \\
\text { attention" syndrome, difficulty } \\
\text { getting buy-in for change } \\
\text { initiatives }\end{array}$ & $\begin{array}{l}\text { Marketing leads M\&A and other change } \\
\text { initiatives } \\
\text { - Communications leadership } \\
\text { - "Walking the talk" }\end{array}$ \\
\hline More tactical than strategic & Firefighting, CYA behavior & $\begin{array}{l}\text { Marketing is valued strategic partner to } \\
\text { CEO and C-team }\end{array}$ \\
\hline
\end{tabular}

implementation. Key players in marketing and other cross-functional organizations, such as sales and product development, need to be invited into the process early on and need to stay involved to achieve stakeholder ownership and buy-in.

The effort, however, yields impressive rewards. MO has the power to re-position and re-energize a company's marketing function, moving it past stubborn barriers to unprecedented levels of performance and success. It creates the type of marketing organization where DAM, MOM and other technology initiatives are positioned for success. Even better is the effect MO has on the stature of marketing in enterprise. Leveraging the discipline and rewards of an MO approach places marketing in the perfect position to influence strategic decisions and help increase corporate revenue, decrease costs and sustain high levels of customer and employee satisfaction. Bottom line, it is a no-brainer for DAM professionals. If your organization has not yet embraced MO, you have the opportunity to seize leadership, increasing your value to your organization. If you organization is already leveraging $\mathrm{MO}$, you can work to ensure its continued success. Either way, MO enables you to help yourself. 